\title{
La comercialización de vehículos automotores nuevos: análisis con indicadores contables y de gestión del valor
}

\author{
Jorge Alberto Rivera Godoya \\ Luis Eduardo Caicedo Chasoy ${ }^{b}$ \\ Yimmer Dario Araujo Narváez ${ }^{c}$
}

\begin{abstract}
Información del artículo
Recibido: 27/06/2020

Aceptado: 30/05/2021

Clasificación JEL:

G10, G32, M40, L81

Este es un artículo Open Access bajo la licencia CC BY NC [https://creativecommons.org/licenses/by-nc/4.0]

Enlace DOI

https://doi.org/10.24142/rvc.n23a5

Sugerencia de citación

- Rivera, J., Caicedo, L. y Araujo,

Y. (2021). La comercialización de vehículos automotores nuevos: análisis con indicadores contables y de gestión del valor. Revista Visión Contable, 23, $103-132$. https://doi. org/10.24142/rvc.n23a5
\end{abstract}

\begin{abstract}
The commercialization of new motor vehicles: analysis with accounting and value management indicators
\end{abstract}

\section{Resumen}

El fin del presente trabajo es evaluar la actividad financiera del sector comercio de vehículos automotores nuevos en Colombia durante 2013 y 2018 , siguiendo como método el análisis de índices contables y de valor económico agregado (EVA) que determinan su evolución, eficiencia, eficacia y efectividad. Se descubre que este sector logra rendimientos contables que fluctúan de la misma forma como lo hace la eficacia en la administración de costos y gastos. No obstante, destruye valor económico agregado, sin importar el aumento de los activos y las ventas; esto ocurre porque la ganancia que proporciona el activo neto operacional es inferior al costo de los recursos financieros. Estas revelaciones pudieran ser ampliadas con investigaciones para agrupaciones etarios y de tamaño semejantes.

\section{Palabras clave}

Valor económico agregado (EVA); valor de mercado agregado (VMA); desempeño financiero; indicadores financieros de eficiencia, efectividad y eficacia; sector comercio de vehículos automotores nuevos en Colombia.

\section{Abstract}

The purpose of this work is to evaluate the financial activity of the new motor vehicle trade sector in Colombia during 2013 and 2018, following as a method the analysis of accounting and economic value added (EVA) indices that determine its evolution, efficiency, efficay and effectiveness. This sector is found to achieve accounting returns that fluctuate in the same way as cost and expense management effectiveness does. However, it destroys added economic value, regardless of the increase in assets and sales; This occurs because the profit provided by the operating net asset is less than the cost of financial resources. These disclosures could be expanded with investigations for age groups and groups of similar size.

\section{Keywords}

Economic value added (EVA); market value added; financial performance; efficiency, effectiveness, and efficacy financial indicators; trade sector new motor vehicles in Colombia

a Doctor en Ciencias Económicas y Empresariales. Profesor titular de la Facultad de Ciencias de Administración de la Universidad del Valle, Cali (Colombia). Correo electrónico: jorge. rivera@correounivalle.edu.co. https://orcid.org/0000-0003-2319-1674

b Contador Público (c), Universidad del Valle, Cali (Colombia). Correo electrónico: luis.chasoy@ correounivalle.edu.co. https://orcid.org/0000-0001-7175-6452<?>

- Contador Público (c), Universidad del Valle, Cali (Colombia). Correo electrónico: yimmer. araujo@correounivalle.edu.co. https://orcid.org/0000-0002-4893-3630 


\section{Introducción}

Las empresas dedicadas a la venta de vehículos automotores nuevos en Colombia han impulsado el empleo y el desarrollo de sectores relacionados, como el asegurador, los servicios financieros, mantenimiento y peaje, el de autopartes, además del recaudo de mayores impuestos municipales; su potencial de crecimiento es alto, dado su bajo índice de motorización mundial, la necesidad de renovar el parque automotor para seguir compromisos de menor daño ambiental y de seguridad, y que existe una clase media con mejores ingresos per cápita (Santamaría, 2019). Sin embargo, su desempeño financiero en los últimos años ha sido poco analizado, y menos desde una perspectiva de saber cuál ha sido su efectividad para alcanzar utilidades sobre los activos o el patrimonio y si ha creado valor económico agregado, siendo ésta la intención principal de la investigación.

La metodología aplicada se fundamenta en un diagnóstico financiero para el sexenio 2013-2018, realizando un análisis de datos históricos contables y de mercado, que logren estimar el crecimiento, la eficiencia en la utilización de activos, la eficacia en la administración de gastos operativos y financieros y el apalancamiento financiero como factores que inciden sobre la efectividad y la utilidad residual, siendo esta última la que determinará si se crea o destruye valor.

Los resultados del estudio muestran que los activos y ventas aumentaron durante el sexenio -salvo una caída en el 2015-; se lograron rendimientos contables, cuyo sentido variable obedeció a los altibajos de la eficacia en la administración de costos y gastos, que es amplificada con un apalancamiento financiero positivo. Sin embargo, el sector de negociación de vehículos automotores nuevos en Colombia destruye valor económico agregado (EVA) cada año, dando como resultado un valor de mercado agregado (VMA) negativo en los seis años, como consecuencia del logro de un rendimiento del activo neto operacional más bajo que el costo de los recursos financieros, a pesar de haber mantenido un aumento continuo de sus activos y ventas. Lo evidenciado se coteja con información de sociedades de mayor tamaño de este sector en Colombia y con indicadores del sector afín en EE. UU.

El trabajo se estructura de la siguiente manera: se inicia con el marco teórico y metodología, escogiendo y definiendo los indicadores financieros más pertinentes para la investigación; luego, se exponen e interpretan algunos de los más importantes indicadores de la gestión financiera de otros sectores análogos en el contorno nacional e internacional, que sirven como 
referentes; después, se reseña brevemente el sector comercio de vehículos automotores nuevos en Colombia; posteriormente, se examinan los indicadores que calculan el desenvolvimiento financiero de las organizaciones del sector en el sexenio; a continuación, se confrontan estos hallazgos con los declarados en fuentes referentes, y para terminar, se concluye sobre los descubrimientos más destacados del trabajo investigativo.

\section{Marco teórico y metodología}

Para diagnosticar la gestión financiera del sector de negocios de nuevos vehículos automotores en Colombia entre el 2013 y el 2018, se siguió un enfoque cuantitativo de investigación y se utilizó como metodología el análisis estático, de series temporales y de índices contables (Gitman \& Zutter, 2016, p. 71) y de gerencia del valor que estuvieran más relacionados con la apreciación del ejercicio financiero de organizaciones pertenecientes a un sector real de la economía.

En el trabajo, se escogieron los siguientes indicadores contables que miden el crecimiento, la eficiencia, la eficacia y la efectividad, y los siguientes indicadores de gestión del valor que determinan el EVA y el VMA. Los indicadores de crecimiento cuantifican la evolución del sector conforme al comportamiento de los activos, las ventas y las utilidades netas.

Los índices de rotación de activos miden "la eficiencia con la cual una empresa utiliza sus recursos, en especial los activos operacionales, según la velocidad de recuperación del dinero invertido en cada uno de los mismos" (Ortiz Anaya, 2018, p. 223); entre estos, se destacan la rotación de activos totales, la rotación de activos fijos, la rotación de activos operacionales, la rotación de inventarios y la rotación de cartera (Rivera, 2017, pp. 41-43). Para determinar estos índices, se halla el cociente de las ventas entre la categoría de activo, menos cuando se calcula la rotación de inventarios, en donde el numerador va ser el costo de las ventas, dado que los inventarios están reportados a valor de costo.

Los márgenes de utilidad miden la eficacia que se posee en el control de los costos y gastos de las compañías y su efecto sobre el beneficio, como ocurre con los que repercuten sobre el margen de utilidad bruta, el margen de utilidad operacional, el margen de utilidad operacional después de impuestos y el margen de utilidad neta (Rivera, 2017, p. 44-45). Estas razones resultan del cociente de cada una de las utilidades entre las ventas. 
Las ratios de efectividad cuantifican los beneficios que reciben los inversores de las empresas y sus dueños por aportes hechos; los primeros mediante el rendimiento del activo, $R O A$; y los segundos por medio del rendimiento del patrimonio, $R O E^{1}$ (Ross, Westerfield \& Jordan, 2018, p. 64). En el sistema Dupont se establece que el $R O A$ "depende de dos factores: las ventas que la compañía genera a partir de sus activos (rotación de activos) y la ganancia que obtiene sobre cada dólar de ventas (margen de utilidad de operación)" (Brealey, Myers \& Allen, 2015, p. 715) y se determina mediante su producto; en tanto con el sistema Dupont ampliado, el $R O E$ precisa de tres factores: el margen de utilidad neta, la rotación de activos y el multiplicador del capital contable ${ }^{2}$ (Brigham \& Ehrhardt, 2018). En otras palabras, la efectividad medida por el $R O A$ es igual al producto de la eficiencia por la eficacia; mientras la efectividad que se obtiene por el $R O E$ es equivalente al producto de la eficacia, la eficiencia, y el apalancamiento financiero (Rivera, 2017).

Aunque los indicadores $R O A, R O E$ y la UPA (utilidad por acción) son considerados como unos de los más importantes datos de origen contable para examinar la gestión financiera de las empresas, han sido objetados porque no incluyen el costo de capital propio ni el riesgo (Stern \& Willette, 2014), y, además, están expuestos a ser manipulados (Salaga, Bartosova \& Kicova, 2015), situación que ha conducido a la aparición de recientes modelos de administración basados en el valor, que buscan gestionar el desempeño mediante el cálculo y control de la utilidad residual; donde el más conocido es el EVA (Worthington \& West, 2001).

El EVA es la utilidad residual que resulta de la diferencia entre la utilidad operacional después de impuestos y un cargo por el uso del capital (Stewart, 2000, p. 164), como se formula en la siguiente ecuación:

$$
E V A_{t}=U O D I_{t}-\text { Cargo de capital },
$$

donde $U O D I_{t}$ es la utilidad operativa después de impuestos en el período $t$, en tanto el cargo de capital en el período $t$ es equivalente a:

ROA = utilidad operacional después de impuestos / activo ROE = utilidad neta / patrimonio

2 El multiplicador de capital contable es el cociente de dividir el activo entre el patrimonio; también conocido como el apalancamiento financiero. 
La comercialización de vehículos automotores nuevos: análisis con indicadores contables y de gestión del valor

$$
\text { Cargo de capital }=\left(A N O_{t-1}\right)\left(K o_{t}\right)
$$

siendo $A N O_{t-1}$ el activo neto operacional al comienzo del período; que resulta de sumar al capital de trabajo neto operativo $K T N O_{t-1}$, el activo fijo neto operacional $\mathrm{AFNO}_{t-1}$ :

$$
A N O_{t-1}=K T N O_{t-1}+A F N O_{t-1}
$$

El $K T N O_{t-1}$ representa los activos corrientes operacionales después de descontar los pasivos corrientes sin costo explícito. El $A F N O_{t-1}$ se obtiene de restar la depreciación a los activos fijos operacionales.

El $K o_{t}$ es el promedio ponderado del costo de capital en el período $t$; conforme a Modigliani y Miller (1963, p. 441), se halla de la siguiente manera:

$$
K o_{t}=K e(1-L)+K i(1-t) L
$$

Donde $K e$ es el costo del patrimonio o costo de oportunidad ${ }^{3} . L$ es el nivel de endeudamiento que se obtiene de relacionar la deuda con costo explícito con el $A N O$. Ki es la tasa de interés, pero dado su deducibilidad a la base gravable, el costo de la deuda después de impuestos va a ser igual a: $K i(1-t)$; donde $t$ es la tasa de impuestos corporativa.

Otra forma de hallar el EVA, según Stewart (2000, p. 163), es la siguiente:

$$
E V A=\left(A N O_{t-1}\right)\left[\left(U A I I_{t}\right)(1-t) /\left(A N O_{t-1}\right)-\left(K o_{t}\right)\right]
$$

donde $\left(\sum_{I_{t}}^{U A I}\right)(1-t) / A N O_{t-1}$ es la rentabilidad después de impuestos del $A N O$. A la diferencia entre la rentabilidad después de impuestos del $A N O$ y el promedio ponderado del costo de capital, $K o_{t}$, se le denomina el porcentaje de utilidad o pérdida residual.

\footnotetext{
Como las firmas que constituyen este sector no cotizan en la bolsa de valores, para efectos del cálculo del Ke se acoge a la metodología del CAPM de Pure Play comentada por Rivera \& Alarcón (2012, pp. 89-90).
} 
El valor actual de los EVAs de varios periodos se le conoce como el valor de mercado agregado ; y se halla aplicando la siguiente fórmula:

$$
\mathrm{VMA}=\sum_{\mathrm{j}=1}^{\mathrm{j}=\mathrm{n}} E V A_{\mathrm{j}} /(1+\mathrm{Koj})^{\mathrm{j}}
$$

También se cuantifica el EVA que genera el patrimonio empleando la siguiente ecuación:

$$
\text { EVA del patrimonio } t=\left(\text { Patrimonio }_{t-1}\right)(R O E-K e)
$$

Se examina la gerencia del valor con el $E V A$ y sus factores explicativos: UODI, ANO, Ko, como, también, el EVA del patrimonio y sus factores explicativos: $R O E$, patrimonio y Ke.

Asimismo, se determina el EVA que logra cada unidad monetaria del $A N O$ por medio de la razón EVA/ ANO.

Los resultados del análisis financiero obtenido en este estudio son cotejados con los revelados en otros sectores semejantes al interior del país y con EE. UU.

\section{Estudios de referencia del ejercicio financiero del sector comercio de vehículos automotores nuevos en Colombia}

En la Tabla 1 se han compilado y clasificado los indicadores contables hallados en el período 2013-2018, para un promedio de las 176 compañías más grandes del sector comercio de vehículos automotores nuevos en Colombia (SGCVC), que anualmente suministra la Revista Dinero en una edición especial denominada "Ranking de las 5.000 empresas más grandes de Colombia".

El SGCVC creció en este período. Las ventas y los activos lo hicieron de forma continua, con una corrección en el 2017 en la primera, y en el 2014 en el segundo. El patrimonio y la utilidad neta lo realizaron de forma fluctuante; y solo en un bienio lograron mantener su ascenso: 2017-2018 en el patrimonio y 2015-2016 en la utilidad neta. Únicamente el Ebitda disminuyó con una tendencia oscilante (Tabla 1, parte a).

La rotación de activos fluctuó al año cerca de 1,8 veces, llegando a ser más alta en 2015 (2,0 veces) y más baja en los años 2013, 2015 y 2017 (1,8 veces). Ver parte b de la Tabla 1. 
La comercialización de vehículos automotores nuevos: análisis con indicadores contables y de gestión del valor

\begin{tabular}{|c|c|c|c|c|c|c|c|c|}
\hline \multicolumn{9}{|c|}{$\begin{array}{l}\text { Tabla 1. Indicadores contables promedio de las grandes empresas del sector } \\
\text { comercio de nuevos vehículos automotores en Colombia (2013-2018) }\end{array}$} \\
\hline Indicador & 2013 & 2014 & 2015 & 2016 & 2017 & 2018 & Promedio & $\sigma$ \\
\hline \multicolumn{9}{|c|}{ a. Crecimiento } \\
\hline Ventas (MM\$) & 102.514 & 110.101 & 117.387 & 130.902 & 130.668 & 145.714 & 122.881 & \\
\hline Activos (MM\$) & 57.741 & 55.878 & 66.547 & 69.552 & 72.794 & 77.339 & 66.642 & \\
\hline Patrimonio (MMS) & 24.405 & 16.855 & 26.121 & 23.967 & 25.328 & 27.285 & 23.994 & \\
\hline Utilidad neta (MM\$) & 1.259 & 988 & 1.556 & 2.903 & 1.354 & 2.473 & 1.755 & \\
\hline Ebitda (MM\$) & 2.413 & 2.966 & 1.576 & 3.169 & 4.768 & 1.997 & 2.815 & \\
\hline \multicolumn{9}{|c|}{ b. Eficiencia } \\
\hline Rotación de activos & 1,8 & 2,0 & 1,8 & 1,9 & 1,8 & 1,9 & 1,8 & 0,1 \\
\hline \multicolumn{9}{|c|}{ c. Eficacia } \\
\hline Ebitda/ventas (\%)1 & 2,4 & 2,7 & 1,3 & 2,4 & 3,6 & 1,4 & 2,3 & \\
\hline $\begin{array}{l}\text { Utilidad } \\
\text { neta/ventas (\%) }\end{array}$ & 1,2 & 0,9 & 1,3 & 2,2 & 1,0 & 1,7 & 1,4 & 0,5 \\
\hline \multicolumn{9}{|c|}{ d. Endeudamiento } \\
\hline $\begin{array}{l}\text { Apalancamiento } \\
\text { Financiero (\%) }\end{array}$ & 236,6 & 331,5 & 254,8 & 290,2 & 287,4 & 283,4 & 280,7 & 32,7 \\
\hline \multicolumn{9}{|c|}{ e. Efectividad } \\
\hline ROE (\%) & 5,2 & 5,9 & 6,0 & 12,1 & 5,3 & 9,1 & 7,2 & 2,8 \\
\hline $\begin{array}{l}\text { Número de } \\
\text { Empresas }\end{array}$ & 177 & 182 & 174 & 182 & 171 & 172 & 176 & \\
\hline \multicolumn{9}{|c|}{$\begin{array}{l}\text { Fuente: Elaboración propia, con información de la Revista Dinero (2014, 2015, 2016, 2017, } 2018 \text { y 2019). } \\
\text { Notas: } 1 \text { conocido como margen Ebitda. } \\
\text { MM\$ significa cantidad en millones de COP. }\end{array}$} \\
\hline
\end{tabular}

Los índices ebitda/ventas y utilidad neta/ventas oscilaron en direcciones contrarias, excepto en el 2016 donde subieron. Esto se debió a que las erogaciones por intereses, impuestos, depreciación y amortización influyeron en el cambio de orientación de estos dos indicadores de eficacia. Ambos indicadores solo lograron una continuidad de su aumento en dos años (2016-2017 el primero, y 2015-2016 el segundo) llegando a su máximo nivel de eficacia en 2017 (3,6\%) y 2016 (1,3\%) respectivamente. Este bienio de crecimiento tuvo como precedente el más bajo nivel de eficacia, medido por Ebitda/ventas en el 2015 (1,3\%) y por utilidad neta/ventas en el 2014 $(0,9 \%)$. El promedio del margen ebitda fue de $2,3 \%$ y del margen neto de $1,4 \%$ (Tabla 1, parte c).

Como se aprecia en la Tabla 1, parte d., el apalancamiento financiero varió en los tres primeros años del periodo, y se redujo en los últimos dos años, dejando un promedio en el sexenio de $280,7 \%$; el mayor y menor 
apalancamiento financiero se presentaron en dos años consecutivos 2014 $(331,5 \%)$ y $2015(254,8 \%)$,

El rendimiento promedio del patrimonio mostró una tendencia creciente, interrumpida en el 2017, pasando de 5,2\% en el 2013 a 9,1\% en el 2018; resultado de la mixtura de los comportamientos cambiantes de la rotación de activos, el margen de utilidad neta y el apalancamiento financiero. El promedio de este indicador en el período fue de 7,2\% (parte e, $\mathrm{d}$ y b de la Tabla 1).

De Damodaran (2019) se consiguió información de un promedio de 27 compañías del sector de ventas al por menor automotor en los Estados Unidos de América (SCVEUA) en el período comprendido entre el 2013 y el 2018, que permitió hallar o clasificar los índices de gestión financiera exhibidos en la Tabla 2.

\begin{tabular}{|c|c|c|c|c|c|c|c|c|}
\hline Indicador & 2013 & 2014 & 2015 & 2016 & 2017 & 2018 & Promedio & $\sigma$ \\
\hline EVA (MMUS\$) & 2.347 & 2.297 & 3.313 & 3.219 & 3.015 & 3.022 & 2.869 & \\
\hline UODI (MMUS\$) & 5.392 & 5.522 & 6.716 & 6.537 & 6.509 & 7.641 & 6.386 & \\
\hline $\begin{array}{l}\text { Cargo de capital } \\
\text { (MMUS\$) }\end{array}$ & 3.044 & 3.226 & 3.402 & 3.317 & 3.494 & 4.619 & 3.517 & \\
\hline ANO (MMUS\$) & 42.176 & 49.022 & 53.421 & 59.577 & 62.720 & 67.210 & 55.688 & \\
\hline Ko (\%) & 7,2 & 6,8 & 6,6 & 5,8 & 5,7 & 7,2 & 6,5 & 0,7 \\
\hline UODI/ANO (\%) & 12,8 & 11,3 & 12,6 & 11,0 & 10,4 & 11,4 & 11,6 & 0,9 \\
\hline Ke (\%) & 8,8 & 8,9 & 8,6 & 7,6 & 7,5 & 9,6 & 8,5 & 0,8 \\
\hline $\begin{array}{l}\text { VMA a 01-01-2013 } \\
\text { (MMUS\$) }\end{array}$ & 13.769 & & & & & & & \\
\hline $\begin{array}{l}\text { EVA patrimonio } \\
\text { (MMUS\$) }\end{array}$ & 2.779 & 3.219 & 3.786 & 4.272 & 3.800 & 4.825 & 3.780 & \\
\hline ROE (\%) & 30,8 & 32,3 & 33,9 & 35,6 & 34,3 & 41,5 & 34,7 & 3,7 \\
\hline $\begin{array}{l}\text { Patrimonio } \\
\text { (MMUS\$) }\end{array}$ & 12.631 & 13.750 & 14.982 & 15.258 & 14.227 & 15.110 & 14.326 & \\
\hline $\begin{array}{l}\text { Número de } \\
\text { empresas }\end{array}$ & 30 & 30 & 26 & 25 & 25 & 24 & 27 & \\
\hline
\end{tabular}

En los seis años evaluados, este sector crea valor económico aunque sin seguir ninguna tendencia, salvo su hundimiento entre el 2016-2017. Preci- 
samente esta caída había tenido como precedente el mayor EVA alcanzado en el período, ocurrida en el 2015 (\$US 3.313), que a su vez era antecedida por un año donde se presentó el menor valor alcanzado en el sexenio (\$US 2.297), demostrando su variabilidad. Este comportamiento fue similar a la orientación de la utilidad operacional después de impuestos (UODI) a partir del 2015, y solo se diferenció a la orientación del cargo de capital en los años 2014 y 2017. El cargo de capital creció a la par con el ANO, salvo una caída en el 2016, pero se diferenció del Ko que se fue reduciendo hasta el penúltimo año. Se aprecia un cargo de capital inferior a la UODI cada año, al igual que Ko comparada con la UODI/ANO; forjando un porcentaje promedio de beneficio residual para los inversionistas del 5,1\% en el sexenio (la diferencia entre $11,6 \%$ y $6,5 \%$ ).

El acumulado de los EVAs creados durante los seis años fue de US\$ 37.728 MM a 1 de enero de 2012, lo que demuestra que en ese sexenio el sector cumplió con su objetivo financiero de generar valor económico. El EVA del patrimonio fue positivo y creciente a lo largo del sexenio, con un ajuste en el 2017; manteniendo una relación directa con el $R O E$ y el patrimonio. El motivo por el que se crea valor para los accionistas fue que el $R O E$ promedio del sector superó sus expectativas de rendimiento promedio en un $26,5 \%$ ( $34,7 \%$ menos $8,5 \%)$.

\section{El sector comercio de vehículos automotores nuevos en Colombia (SCVC)}

En Colombia las empresas de este sector se clasifican en el CIIU 4511, que concierne al comercio de vehículos automotores nuevos. Esta clase de grupo incluye:

El comercio al por mayor y al por menor de vehículos automotores nuevos para pasajeros, incluso vehículos especiales (ambulancias, casas rodantes, microbuses, vehículos de camping, caravanas, entre otros), vehículos con tracción tipo campero (todo terreno), y otros vehículos automotores para pasajeros con mecanismos de conducción similares a los de los automóviles, así como el comercio de camiones, remolques y semirremolques. Las actividades de venta de vehículos por consignación, por comisión o por contrata (intermediarios), como también la compra y venta de contenedores especial- 
mente diseñados y equipados para su uso en uno o más medios de transporte (DANE, 2012, p. 308).

En el período 2014-2018, el crecimiento del sector comercio al por mayor y al detal ha sido igual o superior al crecimiento total de la economía del país, como se aprecia en la Tabla 3. En todo el sexenio evaluado, solo se fue inferior en 2013. Esto muestra el empuje que ofrece este sector al crecimiento de la economía; con una participación que oscila entre un 7,4\% y un $7,6 \%$ del PIB nacional.

\begin{tabular}{|l|c|c|c|c|c|c|}
\hline Tabla 3. Crecimiento del sector comercio en Colombia \\
\hline & $\mathbf{2 0 1 3}$ & $\mathbf{2 0 1 4}$ & $\mathbf{2 0 1 5}$ & $\mathbf{2 0 1 6}$ & $\mathbf{2 0 1 7}$ & $\mathbf{2 0 1 8}$ \\
\hline Crecimiento del sector comercio (\%) & 4,6 & 4,9 & 3,0 & 3,8 & 1,6 & 3,0 \\
\hline Participación del sector comercio al PIB (\%) & 7,4 & 7,4 & 7,4 & 7,5 & 7,5 & 7,6 \\
\hline Crecimiento del PIB (\%) & 5,1 & 4,5 & 3,0 & 2,1 & 1,4 & 2,5 \\
\hline Fuente: Elaboración propia basándose en DANE (2020). & & & & \\
\hline
\end{tabular}

En Colombia, las ventas de vehículos nuevos se redujeron en un 12,9\% en este sexenio, pasando de 294.835 unidades en el 2013 a 275.519 en el 2018; presentándose una mayor reducción en los segmentos Van (-77,7\%), comercial pasajeros $(-66,1 \%)$ y comercial de carga mayor a 10,5 toneladas $(-58,7 \%)$; tan solo el utilitario presentó un incremento de $8 \%$ pasando de 77.000 matrículas en el 2013 a 83.129 en el 2018 (Tabla 4). El comercio estuvo concentrado entre los segmentos automóvil $(51,4 \%)$, utilitario $28,8 \%$ ), pick up $(5,4 \%)$, comercial de carga menor a 10,5 toneladas $(4,8 \%)$ y taxi (4,5\%), que, sumados, representan el $94,9 \%$ de las ventas.

\begin{tabular}{|c|c|c|c|c|c|c|c|c|}
\hline Segmento & 2013 & 2014 & 2015 & 2016 & 2017 & 2018 & Promedio & Variación \\
\hline Automóvil & 144.878 & 161.440 & 148.725 & 137.643 & 125.940 & 131.406 & 141.672 & $-9,3 \%$ \\
\hline Utilitario & 77.000 & 92.790 & 77.731 & 71.751 & 73.568 & 83.129 & 79.328 & $8,0 \%$ \\
\hline Pick Up & 19.208 & 18.121 & 12.735 & 12.051 & 12.240 & 15.457 & 14.969 & $-19,5 \%$ \\
\hline $\begin{array}{l}\text { Comercial } \\
\text { Carga }<10,5 T\end{array}$ & 14.949 & 16.778 & 15.000 & 11.815 & 10.399 & 10.593 & 13.256 & $-29,1 \%$ \\
\hline
\end{tabular}


La comercialización de vehículos automotores nuevos: análisis con indicadores contables y de gestión del valor

\begin{tabular}{|l|c|c|c|c|c|c|c|c|}
\hline Segmento & 2013 & 2014 & 2015 & 2016 & 2017 & 2018 & Promedio & Variación \\
\hline Taxi & 15.993 & 15.895 & 14.955 & 9.819 & 8.734 & 8.865 & 12.377 & $-44,6 \%$ \\
\hline $\begin{array}{l}\text { Comercial } \\
\text { Pasajeros }\end{array}$ & 9.099 & 8.821 & 5.664 & 5.290 & 3.729 & 3.086 & 5.948 & $-66,1 \%$ \\
\hline $\begin{array}{l}\text { Comercial } \\
\text { Carga }>10,5 T\end{array}$ & 5.623 & 6.308 & 4.520 & 2.382 & 1.643 & 2.322 & 3.800 & $-58,7 \%$ \\
\hline Van & 8.085 & 6.145 & 4.050 & 2.947 & 1.985 & 1.804 & 4.169 & $-77,7 \%$ \\
\hline Total & 294.835 & 326.298 & 283.380 & 253.698 & 238.238 & 256.662 & 275.519 & $-12,9 \%$ \\
\hline
\end{tabular}

Fuente: Elaboración propia con base en ANDEMOS (2015, p. 6-9, 11), ANDEMOS (2016, p.5), ANDEMOS (2017, p. 10) y ANDEMOS (2019, p. 12).

Al igual que el crecimiento del sector comercio, la venta de vehículos nuevos tuvo su mayor nivel en el 2014, pero después comenzó a descender hasta el 2017, y solo vino a repuntar en el 2018. Este comportamiento se debió en gran parte al ato grado de obsolescencia del parque automotor cuatro ruedas (16 años) que transitan en una estrecha malla vial, en malas condiciones de uso, y a una estructura tributaria que desincentiva su renovación, con mejoras en sus especificidades de seguridad y/o ambientales (EConcept. Análisis económico independiente, 2016).

\section{Desempeño financiero del sector comercio de vehículos automotores nuevos en Colombia (SCVC)}

Las principales fuentes de información requeridas para hallar los índices de desempeño financiero en el período 2013-2018 fueron los estados financieros reportados en la base Benchmark de BPR Asociados Sales \& Credit Management (2019) y en la Superintendencia de Sociedades (2019), de un promedio de 227 sociedades colombianas del sector comercio de vehículos nuevos, distribuidos de la siguiente forma: 213 en el 2013; 229 en el 2014, 237 en el 2015, 234 en el 2016, 221 en el 2017 y 226 en el 2018. En el Anexo se listan con su número de identificación tributaria (NIT).

\section{Evaluación del crecimiento}

Las ventas y activos crecen solamente interrumpido por un descenso en el año 2015, en tanto la utilidad neta fluctúa anualmente. En el sexenio las ventas crecen un $25,6 \%$, los activos un $29,6 \%$ y las utilidades netas $64,4 \%$, 
y sus promedios fueron de \$ 115.913 MM, \$ 64.110 MM y \$ 1.597 MM respectivamente (Tabla 5).

\begin{tabular}{|c|c|c|c|c|c|c|c|}
\hline \multicolumn{8}{|c|}{ Crecimiento (MM\$) } \\
\hline & 2013 & 2014 & 2015 & 2016 & 2017 & 2018 & Promedio \\
\hline Ventas & 105.436 & 109.965 & 105.462 & 118.390 & 123.780 & 132.445 & 115.913 \\
\hline Activos & 55.442 & 62.247 & 58.495 & 67.590 & 69.051 & 71.836 & 64.110 \\
\hline Utilidad neta & 1.347 & 1.404 & 1.022 & 2.441 & 1.154 & 2.215 & 1.597 \\
\hline \multicolumn{8}{|c|}{$\begin{array}{l}\text { Fuente: Elaboración propia basándose en Superintendencia de Sociedades (2019) y Benchmark de BPR } \\
\text { Asociados Sales \& Credit Management (2019). } \\
\text { Nota: MM\$ significa cantidad en millones de COP }\end{array}$} \\
\hline
\end{tabular}

\section{Evaluación de la eficiencia}

La rotación de cartera cayó en el 2014, pero luego crece hasta el penúltimo año y permanece constante en el 2018; en promedio, se rota la cartera 8,1 veces al año, encontrándose una mayor eficiencia en la gestión de cartera en los dos últimos años (9,1 veces) y una menor eficiencia en el año 2014 (6,8 veces). La rotación de inventario decayó entre el 2013 y el 2016; pasando de presentar la mayor eficiencia en el sexenio en el 2013 (4,9 veces) a la menor eficiencia en el 2016 (4,3 veces) y de mantenerse constante entre el 2014 y 2015 (4,6 veces). En los dos últimos años volvió a aumentar hasta alcanzar una rotación de 4,7 veces en el 2018. La rotación de activos fijos creció hasta el 2014, donde logró el nivel más alto (18,2 veces), en los posteriores años cayó, llegando al pico más bajo en el 2017 (4,2 veces), para luego ascender en el 2018 a 9,1 veces. La rotación de activos totales presentó un comportamiento uniforme a lo largo del periodo analizado, con una leve caída ente 2013 ( 1,9 veces) y 2014 ( 1,8 veces). Se observa que en el sexenio la eficiencia con que se manejó cada uno de los activos fue diferente, pero cuando se toman en su totalidad se encontró una estabilidad. En términos generales, en los seis años se tuvo una mayor eficiencia en la gestión de activos fijos ( 12,2 veces), seguida de la gestión de cartera ( 8,1 veces), y posteriormente la gestión de inventarios ( 4,5 veces). Los factores que han incidido en estos cambios responden al comportamiento de las ventas, el costo de ventas y de los activos. Ver Tabla 6. 
La comercialización de vehículos automotores nuevos: análisis con indicadores contables y de gestión del valor

\begin{tabular}{|c|c|c|c|c|c|c|c|}
\hline \multicolumn{8}{|l|}{ Tabla 6} \\
\hline Índices de eficiencia & 2013 & 2014 & 2015 & 2016 & 2017 & 2018 & Promedio \\
\hline \multicolumn{8}{|c|}{ Rotación (veces) } \\
\hline Rotación de cartera & 7,5 & 6,8 & 8,1 & 8,2 & 9,1 & 9,1 & 8,1 \\
\hline Rotación de inventario & 4,9 & 4,6 & 4,6 & 4,2 & 4,3 & 4,7 & 4,5 \\
\hline Rotación de activos fijos & 17,0 & 18,2 & 11,8 & 8,8 & 8,6 & 9,1 & 12,2 \\
\hline Rotación de activos totales & 1,9 & 1,8 & 1,8 & 1,8 & 1,8 & 1,8 & 1,8 \\
\hline
\end{tabular}

Fuente: Elaboración propia basándose en Superintendencia de Sociedades (2019) y Benchmark de BPR Asociados Sales \& Credit Management (2019).

\section{Evaluación de la eficacia}

El comportamiento de los márgenes de utilidad fluctuó en los seis años evaluados, salvo el crecimiento del margen de utilidad bruta en el bienio 20162017, y la fijeza del margen de utilidad neta entre 2013-2014; destacándose el hecho de que todos fueron positivos en cada uno de los años. Los años en que se llegaron a los niveles de eficacia más altos y bajos también variaron: en el caso del margen bruto estos fueron en el 2014 (15,5\%) y 2015 $(14,2 \%)$ respectivamente, con relación al margen de utilidad operacional se presentaron en el $2016(4,3 \%)$ y $2013(2,0 \%)$, y con respecto al margen estos picos se dieron en el $2016(2,1 \%)$ y en el 2017(0,9\%). Las causas de este comportamiento están determinadas por las tendencias de las ventas y las utilidades contables. Ver Tabla 7.

\begin{tabular}{|l|c|c|c|c|c|c|c|}
\hline Tabla 7. Índices de eficacia & $\mathbf{2 0 1 3}$ & $\mathbf{2 0 1 4}$ & $\mathbf{2 0 1 5}$ & $\mathbf{2 0 1 6}$ & $\mathbf{2 0 1 7}$ & $\mathbf{2 0 1 8}$ & Promedio \\
\hline & \multicolumn{7}{|c|}{ Márgenes (\%) } \\
\hline Margen de utilidad bruta & 15,1 & 15,5 & $\mathbf{1 4 , 2}$ & $\mathbf{1 5 , 2}$ & $\mathbf{1 5 , 4}$ & $\mathbf{1 4 , 8}$ & 15,0 \\
\hline Margen de utilidad operacional & 2,0 & 2,9 & 2,5 & 4,3 & 3,4 & 3,7 & 3,1 \\
\hline Margen de utilidad neta & 1,3 & 1,3 & 1,0 & 2,1 & 0,9 & 1,7 & 1,4 \\
\hline
\end{tabular}

Fuente: Elaboración propia basándose en Superintendencia de Sociedades (2019) y Benchmark de BPR Asociados Sales \& Credit Management (2019).

$\mathrm{Al}$ revisar los promedios de los márgenes de utilidad bruta $(15,0 \%)$ y de la utilidad operacional $(3,1 \%)$ se encuentra que el costo de ventas $(85,0 \%)$ y el gasto de venta y administración $(11,9 \%)$, son los desembolsos que más repercuten en la administración eficaz del sector; en tanto las cuentas no 
operacionales valen el $1,7 \%$, produciendo un promedio una utilidad neta de $1,4 \%$.

\section{Evaluación de la efectividad}

En el sexenio se logró un $R O A$ promedio de 3,7\%, producto de la multiplicación de los indicadores: rotación del activo total ( 1,8 veces) y margen de UODI (2,1\%). El ROA fue variante en el transcurso de los seis años, copiando el comportamiento variante del margen de la utilidad operacional después de impuestos, puesto que la rotación del activo total se mostró estable después del 2014 (Tabla 8). Se puede decir, entonces, que ha sido la eficacia en el monitoreo de los costos y gastos la que ha marcado la pauta del comportamiento de la efectividad de este sector para producir beneficios a sus inversionistas, debido a que la eficiencia en el empleo de los activos se ha mantenido invariable.

El ROA más bajo (2,0\%) se presentó en el 2013, siendo este año donde el margen de UODI fue menor (1,0\%), mientras que en el año 2016 sucedió lo contrario: con el $R O A(5,3 \%)$ más alto y un margen de UODI $(3,0 \%)$ superior.

\begin{tabular}{|c|c|c|c|c|c|c|c|c|}
\hline & 2013 & 2014 & 2015 & 2016 & 2017 & 2018 & Promedio & $\sigma$ \\
\hline \multicolumn{9}{|c|}{ Sistema Du Pont } \\
\hline$R O A(\%)$ & 2,0 & 3,5 & 2,7 & 5,3 & 3,9 & 4,8 & 3,7 & 1,2 \\
\hline $\begin{array}{l}\text { Margen de utilidad } \\
\text { operacional después de } \\
\text { impuestos (\%) }\end{array}$ & 1,0 & 2,0 & 1,5 & 3,0 & 2,2 & 2,6 & 2,1 & \\
\hline $\begin{array}{l}\text { Rotación de activos } \\
\text { totales (veces) }\end{array}$ & 1,9 & 1,8 & 1,8 & 1,8 & 1,8 & 1,8 & 1,8 & \\
\hline \multicolumn{9}{|c|}{ Sistema Du Pont Ampliado } \\
\hline$R O E(\%)$ & 6,0 & 6,2 & 5,1 & 10,8 & 4,7 & 8,6 & 6,9 & 2,4 \\
\hline Margen de utilidad neta (\%) & 1,3 & 1,3 & 1,0 & 2,1 & 0,9 & 1,7 & 1,4 & 0,4 \\
\hline $\begin{array}{l}\text { Rotación del activo total } \\
\text { (veces) }\end{array}$ & 1,9 & 1,8 & 1,8 & 1,8 & 1,8 & 1,8 & 1,8 & 0,1 \\
\hline $\begin{array}{l}\text { Apalancamiento } \\
\text { financiero (\%) }\end{array}$ & 246,2 & 274,6 & 290,5 & 299,9 & 281,9 & 278,9 & 278,7 & 18,8 \\
\hline
\end{tabular}

Fuente: Elaboración propia basándose en Superintendencia de Sociedades (2019) y Benchmark de BPR Asociados Sales \& Credit Management (2019). 
Entretanto, el promedio anual del $R O E$ fue de $6,9 \%$, resultado del producto de la rotación del activo total (1,8 veces), con el margen de utilidad neta $(1,4 \%)$, y con el apalancamiento financiero $(278,7 \%)$. En este sexenio el $R O E$ fue positivo y fluctuó ${ }^{4}$ con el paso de los años, siendo proclive al margen de utilidad neta desde el 2015. Los $R O E$ más alto $(10,8 \%)$ y más bajo $(4,7 \%)$ se presentaron en dos años consecutivos, como fue el 2016 y 2017: precisamente en esos años se obtuvieron los márgenes de utilidad neta más alto $(2,1 \%)$ y más bajo $(0,9 \%)$. Aunque el apalancamiento financiero no mantuvo una relación con el $R O E$, si ayudó a incrementarlo, mediante un apalancamiento financiero positivo, dado que el margen neto fue positivo en cada uno de los años. En resumen, se puede decir que el cambio de la efectividad en la consecución de beneficios para los dueños $(R O E)$ de este sector es causada primordialmente por la variación de la eficacia (margen neto) que es acrecentada por el multiplicador financiero; mientras que la estabilidad de la eficiencia (rotación del activo total) en casi todo el sexenio, influyó mínimamente sobre la fluctuación de la efectividad.

Como el $R O E$ promedio (6,9\%) fue mayor que el $R O A$ promedio $(3,7 \%)$, pero con un margen neto promedio $(1,4 \%)$ inferior al margen operacional después de impuestos promedio $(2,1 \%)$, evidencia que a pesar de que los resultados de actividades no operacionales mermaron un $0,7 \%$ la eficacia del control del total de erogaciones fue el apalancamiento financiero $(278,7 \%)$ en el que permitió que el rendimiento de los propietarios superara al de los inversores.

\section{Evaluación del valor económico agregado}

En el sexenio del 2013 al 2018, la organización colombiana promedio del sector compraventa de vehículos automotores nuevos ha destruido valor económico agregado, en cada uno de los años, un promedio de \$ -1.617 MM anuales. La destrucción del EVA oscila en todo lapso estudiado, y entre el 2014 al 2015 pasa de destruir el menor al mayor valor. El EVA sigue una postura semejante al de la UODI y cargo de capital, excepto en el 2015 para este último. Cada año, la UODI fue inferior al cargo de capital, demostrando que los recursos invertidos lograron producir unos beneficios, pero estos fueron menores a los requeridos por los inversionistas; éstos pretendían

4 Aunque de una forma más pronunciadas que el ROA: La $\sigma$ del ROE fue del 2,4\%, mientras que la del ROA fue del $1,2 \%$. 
ganar por lo menos \$ 4.043 MM anuales, pero solo lograron \$ 2.426 MM (Tabla 9).

En la parte a de la Tabla 9 se muestran los inductores del cargo de capital: el ANO después de caer en el 2014, aumenta en los siguientes años; llegando a un promedio anual de \$ $34.053 \mathrm{MM}$; mientras que el promedio ponderado del costo de capital presenta una primera etapa de crecimiento hasta 2015, y a partir del 2016 una etapa de descenso hasta final del período; alcanzando a un promedio del 11,8\%.

En la parte b de la Tabla 9 y en la Tabla 4 se exponen los inductores de la UODI: la utilidad antes de intereses e impuestos (UAII) y los impuestos presentaron una relación positiva con la UODI, excepto para el 2015 en los impuestos. Además, la UAII siguió la misma dirección de las cuentas que la componen, tales como las ventas, el costo de ventas, la utilidad bruta y el gasto de administración, salvo en el 2017; únicamente el gasto de ventas se apartó de esta directriz.

En la parte c de la Tabla 9 se presentan los inductores del ANO, que revelan solo una relación positiva con el AFNO, pues el KTNO osciló anualmente. El AFNO representó casi un 36,5\% del ANO: el AFNO promedio fue de \$12.422 MM, a la vez que el KTNO promedio fue de \$21.631 MM.

En la parte d. de la Tabla 9 figuran los inductores del Ko, que indican que su direccionamiento estuvo más atado a la tendencia del Ke, excepto en el último año, que al comportamiento de Ki; mientras que su endeudamiento también siguió la tendencia del Ko, salvo en el 2015.

El Ke fue mayor al Ki a lo largo del sexenio, que al final arrojó un promedio de: $\mathrm{Ke}=18,0 \%$, que fue superior a $\mathrm{Ki}=8,6 \%$.

\begin{tabular}{|l|c|c|c|c|c|c|c|}
\hline \multicolumn{7}{|l|}{ Tabla 9. EVA promedio por compañía y sus inductores } \\
\hline & 2013 & 2014 & 2015 & 2016 & 2017 & 2018 & Promedio \\
\hline EVA (MM\$) & -1.481 & -976 & -2.638 & -1.578 & -1.903 & -1.127 & -1.617 \\
\hline UODI (MM\$) & 1.100 & 2.169 & 1.583 & 3.554 & 2.672 & 3.477 & 2.426 \\
\hline $\begin{array}{l}\text { Cargo de capital } \\
\text { (MM\$) }\end{array}$ & 2.581 & 3.145 & 4.220 & 5.132 & 4.575 & 4.604 & 4.043 \\
\hline ANO (MM\$) & 26.804 & 28.255 & 30.825 & 38.704 & 39.515 & 40.215 & 34.053 \\
\hline Ko (\%) & 9,6 & 11,1 & 13,7 & 13,3 & 11,6 & 11,4 & 11,8 \\
\hline & 2.067 & 3.185 & 2.629 & 5.098 & 4.165 & 4.890 & 3.672 \\
\hline
\end{tabular}


La comercialización de vehículos automotores nuevos: análisis con indicadores contables y de gestión del valor

\begin{tabular}{|c|c|c|c|c|c|c|c|}
\hline & 2013 & 2014 & 2015 & 2016 & 2017 & 2018 & Promedio \\
\hline Impuestos (MM\$) & 967 & 1.016 & 1.046 & 1.544 & 1.493 & 1.413 & 1.246 \\
\hline Utilidad bruta (MM\$) & 15.889 & 17.083 & 15.003 & 17.995 & 19.066 & 19.546 & 17.430 \\
\hline Costo de venta (MM\$) & 89.548 & 92.882 & 90.459 & 100.395 & 104.714 & 112.899 & 98.483 \\
\hline $\begin{array}{l}\text { Gastos de Admón. } \\
\text { (MM\$) }\end{array}$ & 3.011 & 3.476 & 3.405 & 4.091 & 4.250 & 4.591 & 3.804 \\
\hline Gastos de venta (MM\$) & 10.810 & 10.422 & 9.290 & 10.072 & 11.847 & 11.025 & 10.578 \\
\hline \multicolumn{8}{|c|}{ c. Inductores del ANO } \\
\hline KTNO (MM\$) & 19.071 & 20.707 & 20.049 & 23.759 & 22.927 & 23.271 & 21.631 \\
\hline AFNO (MM\$) & 7.732 & 7.548 & 10.777 & 14.944 & 16.588 & 16.944 & 12.422 \\
\hline \multicolumn{8}{|c|}{ d. Inductores del Ko } \\
\hline Ke (\%) & 14,4 & 19,6 & 23,1 & 17,5 & 16,2 & 16,9 & 18,0 \\
\hline Ki '(\%) & 7,4 & 7,2 & 8,0 & 11,4 & 9,8 & 7,8 & 8,6 \\
\hline $\begin{array}{l}\text { Deuda con costo } \\
\text { explícito (MM\$\$) }\end{array}$ & 14.401 & 16.880 & 16.935 & 18.465 & 18.755 & 18.779 & 17.369 \\
\hline L (\%) & 53,7 & 59,7 & 54,9 & 47,7 & 47,5 & 46,7 & 51,7 \\
\hline$t(\%)$ & 25,0 & 25,0 & 25,0 & 25,0 & 34,0 & 33,0 & 27,8 \\
\hline \multicolumn{8}{|c|}{ e. Sistema Dupont de la relación UODI/ANO } \\
\hline UODI/ ANO (\%) & 4,1 & 7,7 & 5,1 & 9,2 & 6,8 & 8,6 & 6,9 \\
\hline UODI/Ventas (\%) & 1,0 & 2,0 & 1,5 & 3,0 & 2,2 & 2,6 & 2,1 \\
\hline Ventas/ANO (veces) & 3,9 & 3,9 & 3,4 & 3,1 & 3,1 & 3,3 & 3,5 \\
\hline \multicolumn{8}{|c|}{ f. Valor del mercado agregado } \\
\hline $\begin{array}{l}\text { VMA a 01-01-2013 } \\
\text { (MM\$) }\end{array}$ & -6.727 & & & & & & \\
\hline \multicolumn{8}{|c|}{$\begin{array}{l}\text { Fuente: Elaboración propia basándose en Superintendencia de Sociedades (2019), Benchmark de BPR } \\
\text { Asociados Sales \& Credit Management (2019), Damodaran (2019), y Superintendencia Financiera de } \\
\text { Colombia (2019). } \\
\text { Notas: MM\$ significa cantidad en millones de COP. } \\
\text { 'interés anual promedio de crédito preferencial o corporativo traído de la Superintendencia Financiera } \\
\text { de Colombia (2019) }\end{array}$} \\
\hline
\end{tabular}

[COLOMBIA] 
El VMA del sector compraventa de vehículos automotores nuevos en Colombia, a enero 1 de 2013, fue de \$ - 6.727 MM, lo que corrobora la pérdida de valor económico durante el sexenio. Pese a que este sector produjo anualmente beneficios, márgenes de utilidades y rentabilidades contables positivos, no fue suficiente para compensar el riesgo asumido por los inversionistas (parte f de la Tabla 9, y Tablas 5, 7 y 8). De otro lado, el EVA del patrimonio fue negativo en todos los años, con tendencia a hacer perder más valor a los propietarios en los tres primeros años, y después de un cambio de orientación en el 2016 comienza a fluctuar en los siguientes años. En los años 2015 y 2016 se presentaron la mayor y menor destrucción de valor del capital propio: $\$ 3.625 \mathrm{MM}$ y $\$ 1.510 \mathrm{MM}$ respectivamente. Su comportamiento fue afín al $R O E$, salvo en el 2014, pero contrario al Ke hasta el 2016. La pérdida residual anual promedio fue de \$-2.503 MM. Se destruyó valor porque su rendimiento del capital propio fue inferior al rendimiento requerido por los propietarios; esto se confirma al equiparar el promedio del $R O E(6,9 \%)$ contra el promedio del Ke (18,0\%), tal como se percibe en la Tabla 10.

\begin{tabular}{|l|c|c|c|c|c|c|c|}
\hline \multicolumn{7}{|l|}{ Tabla 10. EVA promedio por compañía originado por el patrimonio } \\
\hline & $\mathbf{2 0 1 3}$ & $\mathbf{2 0 1 4}$ & $\mathbf{2 0 1 5}$ & $\mathbf{2 0 1 6}$ & $\mathbf{2 0 1 7}$ & $\mathbf{2 0 1 8}$ & Promedio \\
\hline EVA patrimonio (MM\$) & -1.897 & -3.035 & -3.625 & -1.510 & -2.812 & -2.141 & -2.503 \\
\hline ROE (\%) & 6,0 & 6,2 & 5,1 & 10,8 & 4,7 & 8,6 & 6,9 \\
\hline Ke (\%) & 14,4 & 19,6 & 23,1 & 17,5 & 16,2 & 16,9 & 18,0 \\
\hline Patrimonio (MM\$) & 22.515 & 22.669 & 20.135 & 22.540 & 24.494 & 25.760 & 23.019 \\
\hline
\end{tabular}

Fuente: Elaboración propia basándose en Superintendencia de Sociedades (2019),Benchmark de BPR Asociados Sales \& Credit Management (2019), Damodaran (2019) y Superintendencia Financiera de Colombia (2019).

Nota: MM\$ significa cantidad en millones de COP

\section{Análisis y contrastes de los resultadlos}

En este apartado, se contrastan los índices financieros que cuantifican el crecimiento, la eficiencia, la eficacia, la efectividad y el valor económico del sector comercio de vehículos automotores nuevos en Colombia (SCVC) con las cifras extraídas de la revista Dinero, entre los años 2013 al 2018, de las compañías más grandes del sector comercio de vehículos nuevos (SGCVC) y la pesquisa de la base de datos de Damodaran (2019) sobre el sector 
La comercialización de vehículos automotores nuevos: análisis con indicadores contables y de gestión del valor

de ventas al por menor automotor en los Estados Unidos de América (SCVEUA).

\section{Crecimiento}

Las cuantías anuales y promedios del sexenio de las ventas, activos y utilidad neta del SCVC hallados en esta investigación fueron menores a los reportados en las SGCVC, esto, en razón de que este último solo consideró a las compañías colombianas de mayor tamaño. Se observa que las ventas se incrementaron con una caída en un año: 2017 para SGCVC y 2015 para SCVC; también se incrementaron en ambos grupos los activos, aunque con una disminución en el 2015 para SCVC; mientras que la utilidad neta fluctuó a lo largo del período (Tabla 11).

\begin{tabular}{|c|c|c|c|c|c|c|c|}
\hline Indicador & 2013 & 2014 & 2015 & 2016 & 2017 & 2018 & Promedio \\
\hline \multicolumn{8}{|c|}{ SGCVC } \\
\hline Ventas & 102.514 & 110.101 & 117.387 & 130.902 & 130.668 & 145.714 & 122.881 \\
\hline Activos & 57.741 & 55.878 & 66.547 & 69.552 & 72.794 & 77.339 & 66.642 \\
\hline Utilidad neta & 1.259 & 988 & 1.556 & 2.903 & 1.354 & 2.473 & 1.755 \\
\hline \multicolumn{8}{|c|}{ ScVC } \\
\hline Ventas & 105.436 & 109.965 & 105.462 & 118.390 & 123.780 & 132.445 & 115.913 \\
\hline Activos & 55.442 & 62.247 & 58.495 & 67.590 & 69.051 & 71.836 & 64.110 \\
\hline Utilidad neta & 1.347 & 1.404 & 1.022 & 2.441 & 1.154 & 2.215 & 1.597 \\
\hline
\end{tabular}

El crecimiento porcentual de las ventas, activos y utilidad neta en el sexenio fue mayor en el SGCVC, que aumentaron el 42,1\%, 33,9\% y 96,3\% respectivamente, comparado con el alza porcentual en el SCVC que fue en su orden del $25,6 \%, 29,6 \%$ y $64,4 \%$.

\section{Eficiencia}

La rotación promedio del activo total en el SGCVC y en el SCVC fueron iguales ( 1,8 veces); además, la variabilidad de este índice fue semejante en 
los dos sectores $(\sigma=0,1 \text { veces })^{5}$, lo que muestra en términos generales es que las empresas promedio de ambos sectores fueron iguales de eficientes en el empleo de los activos (Tabla 12).

\begin{tabular}{|c|c|c|c|c|c|c|c|c|}
\hline \multicolumn{9}{|c|}{ Tabla 12. Cotejo de los índices de eficiencia } \\
\hline Indicador & 2013 & 2014 & 2015 & 2016 & 2017 & 2018 & Promedio & $\sigma$ \\
\hline \multicolumn{9}{|c|}{ SGCVC } \\
\hline $\begin{array}{l}\text { Rotación del activo } \\
\text { total (veces) }\end{array}$ & 1,8 & 2,0 & 1,8 & 1,9 & 1,8 & 1,9 & 1,8 & 0,1 \\
\hline \multicolumn{9}{|c|}{ ScVC } \\
\hline $\begin{array}{l}\text { Rotación del activo } \\
\text { total (veces) }\end{array}$ & 1,9 & 1,8 & 1,8 & 1,8 & 1,8 & 1,8 & 1,8 & 0,1 \\
\hline \multicolumn{9}{|c|}{ Fuente: Extraído de las Tablas 1 y 6} \\
\hline
\end{tabular}

\section{Eficacia}

En el sexenio los márgenes promedios de utilidad neta en el SGCVC y el SCVC fueron semejantes ( $1,4 \%)$, y aunque en ambos fluctuó este indicador de eficacia, en el SCVC se tuvo una mayor estabilidad $(\sigma=0,4 \%)$ que en el SGCVC (0,5\%). Los márgenes de utilidad neta fueron positivos siempre (Tabla 13).

\begin{tabular}{|c|c|c|c|c|c|c|c|c|}
\hline Indicador & 2013 & 2014 & 2015 & 2016 & 2017 & 2018 & Promedio & $\sigma$ \\
\hline \multicolumn{9}{|c|}{ SGCVC } \\
\hline $\begin{array}{l}\text { Margen de utilidad } \\
\text { neta (\%) }\end{array}$ & 1,2 & 0,9 & 1,3 & 2,2 & 1,0 & 1,7 & 1,4 & 0,5 \\
\hline \multicolumn{9}{|c|}{ SCVC } \\
\hline $\begin{array}{l}\text { Margen de utilidad } \\
\text { neta (\%) }\end{array}$ & 1,3 & 1,3 & 1,0 & 2,1 & 0,9 & 1,7 & 1,4 & 0,4 \\
\hline
\end{tabular}

\footnotetext{
5 Si se determina la variación estándar con dos cifras decimales, se encuentra una mayor variabilidad del SGCVC ( $\sigma=0,08$ veces) comparado con el SCVC $(\sigma=0,06)$.
} 


\section{Apalancamiento financiero}

El multiplicador financiero promedio del SGCVC $(280,7 \%)$ fue mayor que el del SCVC (278,7\%); asimismo, la inestabilidad fue mayor en las compañías grandes (que se confirma cuando se contrapone su desviación estándar, que es de $32,7 \%$ para el SGCVC y $18,8 \%$ para el SCVC); lo que muestra que el uso de una proporción más alta y variable de deuda en el sexenio por parte del SGCVC, la expuso a un mayor riesgo por esta forma de financiación (Tabla 14). En ambos sectores se observa una tendencia a crecer en los primeros cuatro años y a decrecer en el último bienio.

\begin{tabular}{l|c|c|c|c|c|c|c|c|}
\hline \multicolumn{10}{|c|}{ Tabla 14. Cotejo de los índices de apalancamiento financiero } \\
\hline \multicolumn{1}{|c|}{ Sector } & $\mathbf{2 0 1 3}$ & $\mathbf{2 0 1 4}$ & $\mathbf{2 0 1 5}$ & $\mathbf{2 0 1 6}$ & $\mathbf{2 0 1 7}$ & $\mathbf{2 0 1 8}$ & Promedio & $\boldsymbol{\sigma}$ \\
\hline SGCVC (\%) & 236,6 & 331,5 & 254,8 & 290,2 & 287,4 & 283,4 & 280,7 & 32,7 \\
\hline SCVC (\%) & 246,2 & 274,6 & 290,5 & 299,9 & 281,9 & 278,9 & 278,7 & 18,8 \\
\hline
\end{tabular}

\section{Efectividad}

Al comparar el promedio del ROE del SCVC (6,9\%), con el del SGCVC $(7,2 \%)$ y con el del SCVEUA $(34,7 \%)$ se nota una holgada supremacía del sector en Estados Unidos de América, que se refrendó todos los años, aunque con una mayor inestabilidad de su efectividad en el sexenio $(\sigma=3,7 \%)$ a diferencia de la eficacia de las empresas colombianas que mostraron un poco más de estabilidad ( $\sigma=2,8 \%$ en el SGCVC y $\sigma=2,4 \%$ en el SCVC). Ver Tabla 15.

\begin{tabular}{|c|c|c|c|c|c|c|c|c|}
\hline Indicador & 2013 & 2014 & 2015 & 2016 & 2017 & 2018 & Promedio & $\boldsymbol{\sigma}$ \\
\hline \multicolumn{9}{|c|}{ SGCVC } \\
\hline ROE (\%) & 5,2 & 5,9 & 6,0 & 12,1 & 5,3 & 9,1 & 7,2 & 2,8 \\
\hline \multicolumn{9}{|c|}{ ScVC } \\
\hline ROE (\%) & 6,0 & 6,2 & 5,1 & 10,8 & 4,7 & 8,6 & 6,9 & 2,4 \\
\hline \multicolumn{9}{|c|}{ SCVEUA } \\
\hline ROE (\%) & 30,8 & 32,3 & 33,9 & 35,6 & 34,3 & 41,5 & 34,7 & 3,7 \\
\hline \multicolumn{9}{|c|}{ Fuente: Extraído de las Tablas 1,2 y 8.} \\
\hline
\end{tabular}


Al equiparar el $R O E$ de los dos grupos de empresas colombianas, se encontró que éste fue menor en el SCVC, debido a que presentó un menor apalancamiento financiero ( $278,7 \%$ vs $280,7 \%$ en el SGCVC), dado que ambos grupos fueron iguales de eficaces y eficientes en la administración de erogaciones y manejo de activos. También se detecta una menor oscilación del $R O E$ del SCVC en contraste con el encontrado en el SGCVC en virtud de que el margen neto y el multiplicador financiero fueron más constantes ${ }^{6}$.

Estos resultados muestran que la menor efectividad del SCVC con relación a las SGCVC se fundamentó en su menor aprovechamiento de un apalancamiento financiero positivo, puesto que logró mantener la misma eficacia y eficiencia lograda por el promedio de las compañías grandes de este sector.

\section{Valor económico agregado}

El EVA del SCVC en los seis años examinados fue negativo; por su parte, en ese mismo tiempo en Estados Unidos de América fue positivo ${ }^{7}$; y en ambos fue fluctuante durante el período analizado. De otro lado, cuando se confronta el EVA del patrimonio, se percibe que este fue negativo año a año en Colombia, en contraste con los montos anuales positivos en Estados Unidos de América (Tabla 16, partes a, b, c y d).

$\mathrm{Al}$ chequear los inductores del EVA se encontró que el promedio de la UODI/ANO fue menor en el SCVC en relación con el SCVEUA (6,9\% vs $11,6 \%)$, mientras que el promedio del Ko fue mayor en el SCVC con respecto al SCVEUA (11,8\% versus $6,5 \%)$, por lo tanto, tuvo como efecto un promedio porcentual de pérdida residual del $-4,9 \%$ en el SCVC, frente a un promedio porcentual de utilidad residual del 5,1\% en el SCVEUA.

El Ko fue superior en el SCVC en todos los años, lo que demuestra la repercusión del riesgo país; especialmente en el bienio 2015-2016.

$\mathrm{Al}$ descomponer los componentes del EVA del patrimonio, como son el $R O E$ y el Ke del SCVC y del SCVEUA, se encontró que ROE del SCVC fue inferior anualmente $y$, por consiguiente, en promedio de los seis años con-

6 La $\sigma$ del margen neto en el SCVC fue de 0,4\%, entretanto en el SGCVC fue de 0,5\%, y la $\sigma$ del apalancamiento financiero en el SCVC fue $18,8 \%$, frente a $32,7 \%$ en las GSCVC; mientras que la $\sigma$ de la rotación de activos fue la misma para el SCVC y SGCVC (0,1 veces). Ver Tablas 1 y 8.

7 El VMA del sexenio fue negativo para el SCVC (\$ -6.727 MM) y positivo para el SCVEUA (US\$ 13.769 MM). 
La comercialización de vehículos automotores nuevos: análisis con indicadores contables y de gestión del valor

siderados (6,9\% frente a un 34,7\% presentado en el SCVEUA), a la vez que el Ke del SCVC fue superior en todos los años y por ende en el promedio del sexenio (18,0\% frente a un $8,5 \%$ en el SCVEUA). Esto evidencia que la rentabilidad exigida por los dueños del SCVC no alcanzó a ser recompensada por la rentabilidad que alcanzó este sector, así como ocurrió en el SCVEUA.

\begin{tabular}{|c|c|c|c|c|c|c|c|c|}
\hline \multicolumn{9}{|l|}{ Tabla 16} \\
\hline $\begin{array}{l}\text { Cotejo del EVA } \\
\text { promedio por } \\
\text { compañía y sus } \\
\text { inductores }\end{array}$ & 2013 & 2014 & 2015 & 2016 & 2017 & 2018 & promedio & $\sigma$ \\
\hline \multicolumn{9}{|c|}{ a. EVA: SCVC } \\
\hline EVA (MM\$) & -1.481 & -976 & -2.638 & -1.578 & -1.903 & -1.127 & -1.617 & \\
\hline UODI/ANO \% & 4,1 & 7,7 & 5,1 & 9,2 & 6,8 & 8,6 & 6,9 & 2,0 \\
\hline Ko (\%) & 9,6 & 11,1 & 13,7 & 13,3 & 11,6 & 11,4 & 11,8 & 1,5 \\
\hline ANO (MM\$) & 26.804 & 28.255 & 30.825 & 38.704 & 39.515 & 40.215 & 34.053 & \\
\hline \multicolumn{9}{|c|}{ EVA: SCVEUA } \\
\hline EVA (MMUS\$) & 2.347 & 2.297 & 3.313 & 3.219 & 3.015 & 3.022 & 2.869 & \\
\hline UODI/ANO \% & 12,8 & 11,3 & 12,6 & 11,0 & 10,4 & 11,4 & 11,6 & 0,9 \\
\hline Ko $(\%)$ & 7,2 & 6,8 & 6,6 & 5,8 & 5,7 & 7,2 & 6,5 & 0,7 \\
\hline ANO (MMUS\$) & 42.176 & 49.022 & 53.421 & 59.577 & 62.720 & 67.210 & 55.688 & \\
\hline \multicolumn{9}{|c|}{ EVA del patrimonio: SCVC } \\
\hline $\begin{array}{l}\text { EVA patrimonio } \\
\text { (MM\$) }\end{array}$ & -1.897 & -3.035 & -3.625 & -1.510 & -2.812 & -2.141 & -2.503 & \\
\hline ROE (\%) & 6,0 & 6,2 & 5,1 & 10,8 & 4,7 & 8,6 & 6,9 & 2,4 \\
\hline Ke (\%) & 14,4 & 19,6 & 23,1 & 17,5 & 16,2 & 16,9 & 18,0 & 3,0 \\
\hline Patrimonio (MM\$) & 22.515 & 22.669 & 20.135 & 22.540 & 24.494 & 25.760 & 23.019 & \\
\hline \multicolumn{9}{|c|}{ EVA del patrimonio: SCVEUA } \\
\hline $\begin{array}{l}\text { EVA patrimonio } \\
\text { (MMUS\$) }\end{array}$ & 2.779 & 3.219 & 3.786 & 4.272 & 3.800 & 4.825 & 3.780 & \\
\hline ROE (\%) & 30,8 & 32,3 & 33,9 & 35,6 & 34,3 & 41,5 & 34,7 & 3,7 \\
\hline Ke $(\%)$ & 8,8 & 8,9 & 8,6 & 7,6 & 7,5 & 9,6 & 8,5 & 0,8 \\
\hline Patrimonio (MMUS\$) & 12.631 & 13.750 & 14.982 & 15.258 & 14.227 & 15.110 & 14.326 & \\
\hline
\end{tabular}


Los inductores de rendimiento del EVA y del EVA del patrimonio fueron más constantes en el sector colombiano de negocios de nuevos vehículos automotores, en comparación con el sector equivalente en EE. UU. (excepto el $\mathrm{Ke}$ ), como se puede ratificar al cotejar la $\sigma$ de razón UODI/ANO $(0,9 \%$ en el SCVC contra el $2,0 \%$ en el SCVEUA), del Ko ( $0,7 \%$ en el SCVC vs $1,5 \%$ en el SCVEUA), del ROE ( $2,4 \%$ en el SCVC vs $3,7 \%$ en el SCVEUA) y del Ke ( $3,0 \%$ en el SCVC y $0,8 \%$ en el SCVEUA).

En la tabla 17 se muestra el EVA total y del capital propio por cada unidad monetaria de inversión. EL indicador EVA/ANO fue negativo para el SCVC en los seis años, mientras que para el SCVEUA sucedió lo contrario, fue positivo. En promedio, la empresa perteneciente a este sector en Colombia destruye $\$ 0,05$ por cada peso colocado por sus inversionistas, mientras que la empresa promedio de este sector en Estados Unidos de América crea $\$$ US 0,05 por cada dólar invertido por sus dueños y prestamistas. El indicador EVA capital propio / patrimonio fue negativo para el SCVC año a año; mientras que para el SCVEUA fue positivo. La empresa promedio del SCVC destruye $\$ 0,11$ por cada peso invertido por sus dueños, mientras que en EE. UU. la empresa de este sector crea $\$$ US 0,6 por cada dólar colocado por sus propietarios.

\begin{tabular}{|c|c|c|c|c|c|c|c|}
\hline & 2013 & 2014 & 2015 & 2016 & 2017 & 2018 & promedio \\
\hline \multicolumn{8}{|c|}{ EVA / ANO } \\
\hline SCVC & $-0,06$ & $-0,03$ & $-0,09$ & $-0,04$ & $-0,05$ & $-0,03$ & $-0,05$ \\
\hline SCVUSA & 0,06 & 0,05 & 0,06 & 0,05 & 0,05 & 0,04 & 0,05 \\
\hline \multicolumn{8}{|c|}{ EVA capital propio / patrimonio } \\
\hline SCVC & $-0,08$ & $-0,13$ & $-0,18$ & $-0,07$ & $-0,11$ & $-0,08$ & $-0,11$ \\
\hline SCVUSA & 0,22 & 0,23 & 0,25 & 0,28 & 0,27 & 0,32 & 0,26 \\
\hline
\end{tabular}

Fuente: Elaboración propia basándose en Superintendencia de Sociedades (2019), Benchmark de BPR Asociados Sales \& Credit Management (2019), Damodaran (2019) y Superintendencia Financiera de Colombia (2019). 


\section{Conclusiones}

Del estudio hecho al sector comercio de vehículos automotores nuevos en Colombia a lo largo del período 2013-2018, se halló un aumento de sus ventas y activos con una caída en el 2015, así como una variación anual de su utilidad neta. El SGCVC sigue estos comportamientos, salvo que no presenta disminuciones en el 2015, tan solo un hundimiento de las ventas en el 2017.

La efectividad para conseguir utilidades sobre el patrimonio sigue una directriz cambiante año a año, que depende de los vaivenes de la eficacia en la administración de costos y gastos que, por sostenerse en una franja de utilidad, permite que su apalancamiento financiero sea positivo; siendo en ese orden de importancia, los dos factores explicativos de su comportamiento.

El SCVC resultó ser menos efectivo que el SGCVC en el sexenio, dado que el $R O E$ promedio fue inferior ( $8,6 \%$ vs $9,1 \%$ ), sin embargo, fue más estable, al tener menor desviación estándar: $2,4 \%$, contra un 2,8\% en el SGCVC. La menor efectividad se explica porque sacó menos provecho que el SGCVC de los apalancamientos financieros positivos que se le presentaron a ambos; ya que, en la eficacia de la gerencia de costos y gastos, y en la eficiencia en el empleo de los activos había igualado a las presentadas por las grandes empresas de este sector. La mayor estabilidad de la efectividad del SCVC obedeció a la menor inestabilidad tanto del margen neto y como del apalancamiento financiero. Pero cuando el cotejo se efectúa con el SCVEUA, se notó una efectividad más baja, puesto que su $R O E$ fue rebasado más de 5 veces por su homólogo estadounidense, que fue de $34,7 \%$; no obstante, esta efectividad fue más estable en el SCVC ( $\sigma=2,4 \%$ vs $\sigma=3,7 \%$ en el SCVEUA).

Aunque en el sexenio el SCVC tuvo utilidades contables cada año, y tuvo un crecimiento continuo, excepto en el 2015, reflejado en sus activos y ventas, no consiguió beneficios residuales en alguno de ellos, provocando un monto negativo del VMA de \$-6.727 MM. El comportamiento de la destrucción de EVA en el SCVC fue fluctuante cada año. Este hallazgo discrepa del SCVEUA, donde se creó valor en todos los años, aunque también de forma oscilante. El SCVC destruyó valor debido a que la rentabilidad del activo neto operacional no superó el promedio ponderado del costo de capital en alguno de los años considerados, como sí ocurrió en el SCVEUA.

Igualmente, el SCVC destruyó EVA del patrimonio en todos los años, ya que la rentabilidad del patrimonio no nivela el costo de oportunidad de sus dueños, resultados que fueron contrarios a los conseguidos por el SCVEUA, donde este rendimiento supera lo requerido por sus propietarios. 
En términos relativos, se encontró que por cada peso colocado por los inversionistas en una empresa promedio del SCVC, ésta le destruyó \$-0,05; mientras que para los inversionistas del SCVEUA el dólar invertido les creó \$US 0,05.

Si bien este trabajo se analizó los aspectos más relevantes que influyeron sobre el desempeño del SCVC, podría completar con pesquisas similares para grupos de compañías más homogéneos en cuanto a su tamaño, edad, naturaleza jurídica, localización geográfica, y demás aspectos que se reconocen como fundamentales en la literatura financiera y en el medio empresarial. 


\section{Referencias}

ANDEMOS. (2015). Sector automotor. Reporte sector automotor diciembre 2014. Colombia 2014. Recuperado el 20 de febrero de 2020, de http:// www.andemos.org/wp-content/ uploads/2016/08/Informe-Vehiculos-2014-12.pdf

ANDEMOS. (2016). Informe de vehículos diciembre. Colombia 2015. Recuperado el 20 de febrero de 2020, de http://www.andemos.org/ wp-content/uploads/2016/08/Informe-Vehiculos-2015-12.pdf

ANDEMOS. (2017). Informe de vehículos diciembre. Colombia 2016. Recuperado el 20 de febrero de 2020, de http://www.andemos.org/ wp-content/uploads/2017/01/Informe-Vehiculos-2016-12.pdf

ANDEMOS. (2019). Informe de vehículos diciembre. Colombia 2018. Recuperado el 20 de febrero de 2020, de http://www.andemos.org/ wp-content/uploads/2019/01/Informe-Vehiculos-2018-12.pdf

BPR Asociados Sales \& Credit Management. (2019). Benchmark database. Obtenido de sitio web de EMIS: http://bck.securities.com/mainview?sector_id=9999028\&sv=B$\mathrm{CK} \& \mathrm{pc}=\mathrm{CO}$

Brealey, R., Myers, S., \& Allen, F. (2015). Principios de finanzas corporativas (Decimoprimera ed.). México: McGraw-Hill.
Brigham, E., \& Ehrhardt, M. (2018). Finanzas corporativas. Enfoque central (Primera ed.). México: Cengage Learning.

Damodaran, A. (2019). Base de datos en línea. Obtenido de sitio web de Damodaran Online: http://pages. stern.nyu.edu/ adamodar/

DANE. (2012). Clasificación industrial internacional uniforme de todas las actividades económicas. Revisión 4 adaptada para Colombia. CIIU Rev. 4 A.C. Obtenido de https:// www.dane.gov.co/files/nomenclaturas/CIIU_Rev4ac.pdf

DANE. (2020). Producto Interno Bruto -PIB- nacional trimestral. Históricos. Recuperado el 15 de febrero de 2020, de sitio web de DANE: https://www.dane.gov.co/index. php/estadisticas-por-tema/cuentas-nacionales/cuentas-nacionales-trimestrales/historicos-producto-interno-bruto-pib\#base-2015

EConcept. Análisis económico independiente. (2016). El sector de vehículos en Colombia: Características y propuesta de mejora a su régimen Impositivo. Recuperado el 25 de febrero de 2020, de http://www.andemos.org/ wp-content/uploads/2016/12/ EL-SECTOR-DE-VEH\%C3\%8DC U L O S - E N - C O L O M BIA-CARACTER\%C3\%8DSTI- 
CAS-Y-PROPUESTAS-DE-MEJORA-A-SU-R\%C3\%89GIMEN-IMPOSITIVO-VF11.24.2016-ECONCEPT-Sin-Anexo-8.pdf

Joel Stern, J. W. (8 de abril de 2014). A Look Back at the Beginnings of EVA and Value Based Management: An Interview with Joel $\mathrm{M}$. Stern. Journal of Applied Corporate Finance, 26(1), 39-46.

Laerwnce, G., \& Zutter, C. (2016). Principios de administración financiera (Decimocuarta ed.). México: Pearson Education.

Modigliani, F., \& Miller, M. (1963). Corporate income taxes and the cost of capital: a correction. The American economic review, 53(3), 433-443.

Ortiz Anaya, H. (2018). Análisis financiero aplicado, bajo NIIF (Decimosexta ed.). Bogotá: Universidad Externado de Colombia.

Rivera Godoy, J. A. (2017). Introducción a la administración financiera: fundamentos y aplicaciones para crear valor. Cali: Universidad del Valle.

Rivera Godoy, J. A., \& Alarcón Morales, D. S. (2012). El cargo de capital en la evaluación del desempeño financiero de empresas innovadoras de confecciones de Cali. Estudios Gerenciales, 38(123), 85-100. Obtenido de https://www.icesi.edu.co/ revistas/index.php/estudios_gerenciales/article/view/1209/html

Ross, S., Westerfield, R., \& Jordan, B. (2018). Fundamentos de finanzas corporativas (Undécima ed.). México: McGraw-Hill Education.

Salaga, J., Bartosova, V., \& Kicova, E. (2015). Economic value added as a measurement tool of financial performance. Procedia Economics and Finance, 26, 484-489.

Santamaría Salamanca, M. (11 de mayo de 2019). Los números positivos de la industria aumotoriz en Colombia. Revista Semana. Obtenido de https://www. semana.com/contenidos-editoriales/sobre-ruedas/articulo/ industria-automotriz-en-colombia-en-2018/615749/

Stewart, B. (2000). En busca del valor. Barcelona: Ediciones Gestión 2000.

Superintendencia de Sociedades. (2019). Sistema de Información y Riesgo Empresarial (SIREM). Obtenido de sitio web de Superintendencia de Sociedades: https:// www.supersociedades.gov.co/delegatura_aec/estudios_financieros/ Paginas/sirem.aspx

Superintendencia de Sociedades. (2019). Tasa de interés y desembolsos por modalidad de crédito. $\mathrm{Ob}-$ tenido de sitio web de Superinten- 
dencia de Sociedades: https://www. superfinanciera.gov.co/jsp/loader. jsf?IServicio $=$ Publicaciones\&lTipo $=$ publicaciones\&lFuncion $=$ loadContenidoPublicacion\&id $=60955$

Superintendencia Financiera de Colombia. (2019). Tasa de interés y desembolsos por modalidad de crédito. Obtenido de sitio web de Superintendencia Financiera de Colombia: https://www.superfinanciera.gov. co/jsp/loader.jsf?1Servicio=Publicaciones\&lTipo $=$ publicaciones\&lFuncion $=$ loadContenidoPublicacion\&id $=60955$

Worthington, A., \& West, T. (2001). Economic value-added: A review of the theoretical and empirical literature. Asian Review of Accounting, 9(1), 67-86. Obtenido de https:// eprints.qut.edu.au/2568/1/2568. pdf?1321237491 


\section{Anexo}

\section{NIT de las compañías dedicadas al comercio de vehículos automotores nuevos}

\begin{tabular}{|c|c|c|c|c|c|c|}
\hline 860025792 & 860507710 & 802012828 & 800039439 & 800249155 & 900022108 & 860508679 \\
\hline 860002304 & 900737579 & 900353873 & 830115079 & 891801491 & 900824371 & 830513536 \\
\hline 860001307 & 900241676 & 805030706 & 900896197 & 816002886 & 830079832 & 830096048 \\
\hline 900780510 & 900229376 & 800247851 & 890802377 & 891200429 & 800160116 & 900390168 \\
\hline 900780755 & 802000849 & 830006901 & 900380333 & 900225704 & 900406618 & 800181332 \\
\hline 900703240 & 900108579 & 900009847 & 800175223 & 800149138 & 900173556 & 900352122 \\
\hline 830078966 & 890942310 & 900283099 & 891903403 & 830048284 & 900450890 & 900039224 \\
\hline 830004993 & 890922323 & 900315569 & 891409215 & 890001208 & 900056114 & 900670035 \\
\hline 800173557 & 800218155 & 830011616 & 819005725 & 900336249 & 900475635 & 900009890 \\
\hline 900466209 & 816003186 & 800026404 & 900188208 & 800170523 & 900266599 & 900453989 \\
\hline 860509514 & 815000997 & 860001576 & 800215493 & 800250351 & 800146054 & 890924125 \\
\hline 830044266 & 890327282 & 890700179 & 800142319 & 890403472 & 900486495 & 860529896 \\
\hline 900327290 & 900871523 & 900241784 & 800215494 & 891001700 & 900510476 & 900345054 \\
\hline 860047657 & 890911878 & 890924684 & 800129263 & 900297269 & 800160026 & 805000309 \\
\hline 900166896 & 830008804 & 830007334 & 891102600 & 900171022 & 800014107 & 900457810 \\
\hline 860020058 & 890913902 & 800110970 & 900362666 & 860508936 & 830509877 & 890002089 \\
\hline 890903024 & 900329399 & 900978685 & 890100164 & 900545795 & 900010107 & 900593229 \\
\hline 900878893 & 800159244 & 860034604 & 804002832 & 830022354 & 900519790 & 900088089 \\
\hline 800186142 & 900006406 & 900294398 & 900889628 & 817000672 & 900515325 & 830039773 \\
\hline 800041829 & 860056330 & 800165694 & 804014559 & 900694569 & 900405070 & 900462777 \\
\hline 890905627 & 900103237 & 900569531 & 804002724 & 800215496 & 900486347 & 900597369 \\
\hline 860052634 & 860032115 & 860536250 & 900333499 & 804005049 & 900171238 & 800051817 \\
\hline 890200179 & 830065609 & 860023024 & 891100247 & 900164335 & 900188916 & 830124436 \\
\hline 800249704 & 830045752 & 890800100 & 800157892 & 900552393 & 860091235 & 890923417 \\
\hline 860015118 & 890203023 & 890801770 & 890207088 & 830086206 & 900009507 & 846000353 \\
\hline 890301680 & 800084728 & 824001273 & 900084999 & 892301158 & 900216859 & 808003157 \\
\hline 860078024 & 890925058 & 900426895 & 890102782 & 830054299 & 900192630 & 890201902 \\
\hline 860040872 & 890403068 & 900470946 & 820001772 & 811022917 & 832000123 & 900304452 \\
\hline 860069497 & 890700031 & 830039537 & 805026621 & 860401312 & 800253667 & 830025700 \\
\hline 860007884 & 806006435 & 800240258 & 800206234 & 800202170 & 890320141 & 800227256 \\
\hline 860019063 & 804004553 & 860060543 & 830074094 & 890308965 & 860508856 & 860090052 \\
\hline 900759679 & 810000882 & 890300394 & 890802651 & 830040343 & 900540501 & 890920572 \\
\hline 811010832 & 802007207 & 860001778 & 900354959 & 890800120 & 830107139 & 900237133 \\
\hline 890900081 & 891902805 & 800007122 & 900343209 & 805026706 & 800048266 & 900408981 \\
\hline 804012720 & 800035606 & 890904615 & 900252006 & 800045259 & 900622968 & 814005173 \\
\hline 900402392 & 800029569 & 900369627 & 830011015 & 890900234 & 891904029 & 900531238 \\
\hline 860523285 & 890900016 & 860000189 & 890300086 & 800060067 & 900110871 & 890324721 \\
\hline 900428003 & 890504944 & 830140545 & 830079847 & 900692153 & 900038364 & 900096372 \\
\hline 800136269 & 830059253 & 900273463 & 900120532 & 830001730 & 900448624 & 900048374 \\
\hline
\end{tabular}

Fuente: Elaboración propia basándose en Superintendencia de Sociedades (2019) y Benchmark de BPR Asociados Sales \& Credit Management (2019). 